\section{A Almejada Ampliação da Representatividade Cientifica dos "Arquivos"}

$\mathbf{N}$ ESTE PRIMEIrO NúmERO DO ANO de 1999, os "Arquivos Brasileiros de Endocrinologia e Metabologia" atingem mais uma meta do seu processo de crescimento: a tão almejada oficialização da representatividade científica das várias Sociedades Brasileiras de Endocrinologia. Sob a égide da recém criada FEBRASEM - Federação Brasileira de Sociedades de Endocrinologia -, estão finalmente irmanadas a SBEM (Sociedade Brasileira de Endocrinologia e Metabologia), a SBD (Sociedade Brasileira de Diabetes), a ABESO (Associação Brasileira de Estudos sobre a Obesidade) e a SOBEMOM (Sociedade Brasileira de Estudo do Metabolismo Ósseo e Mineral).

As razões para esta unificação são múltiplas e a atividade científica pode até não ser a principal delas, mas é certamente fundamental para alicerçar este grupo de Sociedades que vem se desenvolvendo autonomamente, sem uma representatividade cientifica apropriada.

Neste aspecto não parece restar nenhuma dúvida de que os "Arquivos" devam ser o veículo comum e maior de representação desta nova Federação na área da divulgação científica. Particularmente, creio arriscado e talvez mesmo desnecessário considerar os "Arquivos" como orgão exclusivo de divulgação científica, uma vez que várias outras publicações brasileiras de respeito, ligadas a outras sociedades científicas não necessariamente afiliadas à nossa Federação, como por exemplo a FEBRASGO (Federação Brasileira das Sociedades de Ginecologia e Obstetrícia), possuem gabarito idêntico para divulgar artigos ligados a áreas de conhecimento comuns, como a ginecologia endócrina, a reprodução humana, e as condições associada ao climatério e à menopausa, etc.

É perfeitamente cabível e salutar que um endocrinologista publique seus dados na revista "Reprodução e Climatério", se acreditar que seu público alvo seja mais especificamente os ginecologistas ou indivíduos ligados à reprodução humana, enquanto um pediatra ou radiologista poderá optar pelos Arquivos, se lhes parecer mais adequado divulgar seu trabalho entre os endocrinologistas. Esta troca de informações é sadia e estimulante.

Entretanto insisto - e desculpem-me se aborreço alguns com esta insistência -, que não deveriam ser priorizadas pelos nossos associados e/ou afiliados fontes menos adequadas de divulgação científica para a publicação de seus artigos; refiro-me, mais uma vez, àquelas revistas sem qualquer identificação com associações médico-científicas oficiais e, portanto, sem sua devida chancela de qualidade; revistas de interesse apenas comercial, sem estofo para merecer nossa atenção e desprovidas da necessária responsabilidade científica (onde sempre se encontra a incômoda frase: "não nos responsabilizamos pela opinião emitida nos artigos assinados ...").

Outra situação que merece ser colocada, discutida amplamente durante a reunião do Conselho Editorial dos "Arquivos" no Congresso Brasileiro de Endocrinologia e Metabologia, em São Paulo, é a duplicidade da publicação de dados. Porquanto deva ser considerada inaceitável a simples repetição de um determinado artigo, contendo os mesmos dados ou ape- editorial

Claudio E. Kater

Editor-Chefe, ABE\&M 
nas discretamente maquiados para parecerem diferentes, sua publicação de maneira abreviada ou com determinada ênfase, seguida de outra publicação mais completa, visando um outro público, talvez até internacional, ou com um enfoque distinto do primeiro, pode ser justificável e merecedora de aceitação, desde que sempre seja citada a publicação anterior.

Considera-se, por outro lado, não somente aceitável como até justificada a duplicação de determinada publicação que tenha o objetivo de divulgar e difundir mais amplamente informações importantes $c$ necessárias para a comunidade científica. Este é exatamente o caso da publicação de "guidelines" e consensos, como os que estamos publicando no presente número dos ABE\&M. Os consensos de Diabetes publicados agora de maneira inédita em nossa revista, provavelmente estarão sendo cogitadas para publicação também em outras revistas, como é o caso do Consenso de Diabetes e Gravidez na revista da FEBRASGO e o de complicações crônicas do Diabetes na revista oficial da Sociedade de Oftalmologia e/ou de Nefrologia, por exemplo. O Consenso de
Obesidade já vem sendo exposto há algum tempo a um público amplo da Ámerica Latina e merecerá uma nova versão brevemente, após sugestões e recomendações ulteriores.

Quero deixar consignado que, na dependência da boa aceitação deste formato de publicação especial contendo Consensos de interesse para Endocrinologistas (que será repetido pelo menos no número de Agosto, com o Consenso de Hipertensão, de Dislipidemias e outros), procuraremos manter a norma de publicá-los sempre que conveniente, em números especiais ou suplementos anuais.

Para encerrar, mas não menos importante já que falamos de representatividade, quero parabenizar os novos componentes do Conselho Editorial da revista, recomendados durante a reunião do Conselho Editorial e através de sugestões de outras fontes. Adicionamos quase $50 \%$ de novos nomes, médicos e pesquisadores de reconhecida qualidade e representantes de diversas áreas de atuação científica de todo o Brasil, que irão enriquecer e fortalecer nosso Conselho Editorial. 